\title{
Acute carbon monoxide poisoning -3 years experience in a defined population
}

\author{
J. SydNEY SMITH \\ M.B., B.S. (Sydney) \\ Research Registrar
}

\author{
S. BRANDON \\ M.D. (Durham), D.P.M., D.C.H. \\ Hon. Consultant Psychiatrist and \\ Nuffield Foundation Fellow in Psychiatry
}

The Department of Psychological Medicine, University of Newcastle upon Tyne, and Royal Victoria Infirmary, Newcastle upon Tyne

\section{Summary}

Between 1 January 1965 and 31 December 1967, 206 episodes of carbon monoxide poisoning were known to the coroner or the city hospitals in Newcastle upon Tyne.

The mortality rates were: suicidal exposure $38.2 \%$; accidental exposure $39.7 \%$.

In $21.3 \%$ of suicidal and $18.9 \%$ of accidental exposures recovery was complicated by prolonged delirium suggesting that all degrees of functional or structural neurological damage may have occurred, yet oxygen therapy was given in only $43.8 \%$ of suicidal and $34.5 \%$ of accidental exposures.

In view of the risk of persistent neuropsychiatric sequelae it is suggested that current patterns of management should be revised.

\section{Introduction}

In Britain in 1966 carbon monoxide was the commonest agent of fatal poisoning, both accidental and self-induced (Ministry of Health Report on: Hospital Treatment of Acute Poisoning, 1968), but reliable estimates of the total incidence of exposure or of neuropsychiatric sequelae are not available. Shillito, Drinker \& Shaughnessy (1936) reported that of a cohort of 21,000 people suffering acute carbon monoxide poisoning thirty-nine developed confusional psychoses but few of these suffered permanent neuropsychiatric damage. The methodology employed in this study, however, was so unsound that statistical conclusions are invalid.

The diverse neuropsychiatric abnormalities occurring in the acute phase, commented on by Garland $\&$ Pearce (1967), have been placed in perspective by the clinical study of Bour, Pasquier \& BertrandHardy (1966). Clinical studies to date, however, including that of Meigs \& Hughes (1952), have been based on hospitalized patients selected by their severity and so give no information on the incidence of the various clinical manifestations in the total population exposed.
In this paper we report the preliminary findings of a study of a defined total population. The survivors are being examined to determine the nature and incidence of neuropsychiatric sequelae and this will be the subject of a further communication.

\section{Methods}

Patients suffering acute carbon monoxide poisoning in the period 1 January 1965 to 31 December 1967 were identified from the casualty registers of the two general hospitals serving the Newcastle upon Tyne city area. The casualty notes and relevant medical and psychiatric ward notes were traced. Fatalities were identified from the City Coroner's records for the same period. A search of the records of other medical and psychiatric hospitals within the county of Northumberland revealed that only one patient domiciled in the city had received inpatient treatment outside the city area. This patient was included in our study. Some patients suffering mild exposure may not have come to the attention of medical practitioners though their numbers are likely to have been small.

The total cohort is examined to determine the sources of exposure. Those domiciled in the city are studied separately and form the basis of an epidemiological study. Finally all the patients who presented for treatment are considered to determine the incidence of the various clinical features and the patterns of management.

\section{Results \\ Epidemiological considerations}

Of a total of 206 patients identified, 147 were domiciled in the city area. The breakdown of this material is shown in Table 1. Cases were allotted to one of the diagnostic groups according to the coroner's verdict or admission diagnosis. The records rarely indicated any doubt as to the nature of the exposure. Within the city the mortality rates were: suicidal exposure $38.2 \%$, accidental exposure $39.7 \%$. 
TABle 1. Classification of patients

\begin{tabular}{lccr}
\hline & $\begin{array}{c}\text { Domiciled } \\
\text { in city }\end{array}$ & $\begin{array}{c}\text { Domiciled } \\
\text { outside city }\end{array}$ & Total \\
\hline Attempted suicide & 55 & 23 & 78 \\
Consummated suicide & 34 & 6 & 40 \\
Accidental-survivors & 35 & 22 & 57 \\
Accidental-fatalities & 23 & 6 & 29 \\
Coroner's open verdict & - & 2 & 2 \\
Total & 147 & 59 & 206 \\
\hline
\end{tabular}

Prevalence rates for the city cohort were computed from the 1961 census figures. The sex-specific mean annual prevalence rates are given in Table 2 . A predominance of males is found in all four diagnostic groups.

Fig. 1 depicts the age-specific mean annual prevalence rates for those accidentally exposed. The initial increase in prevalence in the group aged 20-30 years is accounted for principally by occupational exposure in males. With advancing age and mental deterioration, gas appliances tended to be left unlit and accidental exposure became increasingly prevalent. It was also with advancing age that such accidents proved to be fatal, the prevalence of accidental fatalities reaching a maximum of 51.7 per 100,000 per annum at $70-80$ years.

Age-specific rates for self poisoning by carbon monoxide are depicted in Fig. 2. Attempted suicide showed a peak first in the 20-30-year age-group and again at $70-80$ years. Both sexes demonstrated this pattern. The prevalence of consummated suicide

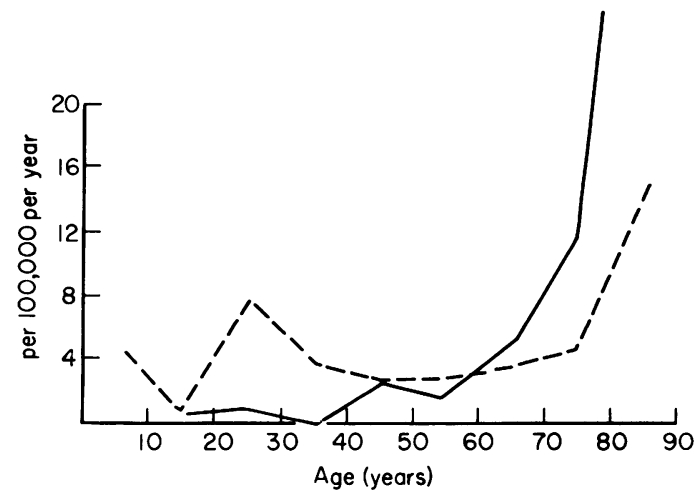

FIG. 1. Age-specific mean annual prevalence rates for accidental population. - Accidental fatalities; - - - acidental survivors.

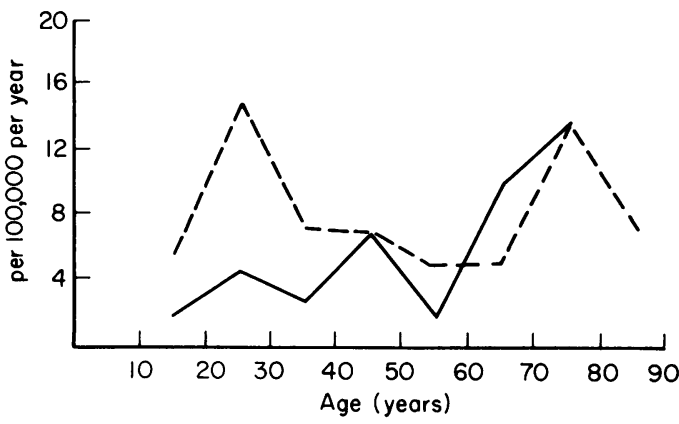

FIG. 2. Age-specific mean annual prevalence rates for suicidal population. - $\longrightarrow$ Consummated suicides; - - - attempted suicides.

TABLE 2. Mean annual prevalence rates, by sex*

\begin{tabular}{lcccc}
\hline & Male & Female & $\begin{array}{c}\text { Male/female } \\
\text { Ratio }\end{array}$ & All persons \\
\hline Attempted suicide & $9 \cdot 3$ & $4 \cdot 5$ & $2 \cdot 0: 1$ & $6 \cdot 8$ \\
Consummated suicide & $5 \cdot 4$ & $3 \cdot 1$ & $1 \cdot 8: 1$ & $4 \cdot 2$ \\
Accidental-survivors & $5 \cdot 9$ & $2 \cdot 8$ & $2 \cdot 1: 1$ & $4 \cdot 3$ \\
Accidental-fatalities & $3 \cdot 3$ & $2 \cdot 4$ & $1 \cdot 4: 1$ & $2 \cdot 8$ \\
Total-city cohort & $23 \cdot 9$ & $12 \cdot 8$ & $1 \cdot 8: 1$ & $18 \cdot 2$ \\
\hline
\end{tabular}

* Per 100,000 per year.

TABLE 3. Source of exposure-accidental

\begin{tabular}{|c|c|c|c|}
\hline & & Survivors & Fatalities \\
\hline Occupational & $\begin{array}{l}\text { Exposure in mine } \\
\text { Gas worker } \\
\text { Garage } \\
\text { Other }\end{array}$ & $\begin{array}{l}2(3 \cdot 5 \%) \\
4(7 \cdot 0 \%) \\
1(1 \cdot 8 \%) \\
3(5 \cdot 3 \%)\end{array}$ & 0 \\
\hline Non-occupational & $\begin{array}{l}\text { Gas leak } \\
\text { Unlit appliance } \\
\text { Conflagration } \\
\text { Car exhaust } \\
\text { Incomplete fuel combustion } \\
\text { Disused workings } \\
\text { Unknown }\end{array}$ & $\begin{array}{l}15(26 \cdot 3 \%) \\
15(26 \cdot 3 \%) \\
3(5 \cdot 3 \%) \\
5(8 \cdot 8 \%) \\
5(8 \cdot 8 \%) \\
0 \\
4(7 \cdot 0 \%)\end{array}$ & $\begin{array}{l}4(13.8 \%) \\
8(27.6 \%) \\
11(37.9 \%) \\
0 \\
1(3.4 \%) \\
2(6.9 \%) \\
3(10.3 \%)\end{array}$ \\
\hline Total & & $57(100.0 \%)$ & $29(100 \cdot 0 \%)$ \\
\hline
\end{tabular}


rose with advanced age, though no fatalities were found over 80 years of age.

\section{Source of exposure}

Tables 3 and 4 indicate the sources of exposure for the total accidental and suicidal populations respectively.

TABLE 4. Source of exposure-suicidal

\begin{tabular}{lcc}
\hline & Attempted & Consummated \\
\hline Household gas & $75(96 \cdot 1 \%)$ & $40(100.0 \%)$ \\
Car exhaust & $2(2.6 \%)$ & 0 \\
Secondary to arson & $1(1.3 \%)$ & \\
Total & $78(100.0 \%)$ & $40(100.0 \%)$ \\
\hline
\end{tabular}

Household gas constituted the principal source of suicidal exposure. In the 'accidental' population, however, it was responsible in $59.6 \%$ of survivors and $41.4 \%$ of fatalities.

A number of people succumbed to the black smoke of fires without suffering significant burns. One patient who attempted suicide by setting fire to her house, escaped burns but was overcome by the smoke. Such black smoke usually contains about $0.1 \%$ carbon monoxide as compared with domestic coal gas which may contain up to $15 \%$.

Motor exhaust fumes which may contain up to $12 \%$ carbon monoxide, constitute a significant source of accidental exposure, but were rarely used by our patients for suicidal purposes. In no case was such exposure fatal.

In $21.8 \%$ of attempted suicides and $17.5 \%$ of consummated suicides, the carbon monoxide exposure was complicated by an overdose of tabletsusually barbiturates.

\section{Clinical features}

On arrival at hospital sixty-eight patients were dead and 138 alive but three died after admission. Of the 138 patients eighty had attempted suicide with carbon monoxide and fifty-eight had been accidentally exposed. These were analysed separately to determine whether suicidal and accidental patients differed significantly in clinical severity.

Abnormal skin colouration. Of the suicidal group, fifty-one $(63.7 \%)$ were considered to be of normal appearance, fourteen $(17.5 \%)$ flushed, seven $(8.8 \%)$ cyanosed, four $(5.0 \%)$ 'cherry pink' and four $(5.0 \%)$ pale.

Forty-four $(75.9 \%)$ of the accidental group were described as having normal colouration, three $(5 \cdot 2 \%)$ were flushed, five $(8.6 \%)$ cyanosed, four $(6.9 \%)$ 'cherry pink' and two $(3.4 \%)$ were pale.

Thus 'cherry pink' colouration was an uncommon finding in our series.

Temperature. Temperatures below $97^{\circ} \mathrm{F}$ were observed in six $(7.5 \%)$ of the suicidal group and one
$(1.7 \%)$ of the accidental group. The lowest temperature was recorded in a 38-year-old woman who presented with delirium, signs of bilateral pyramidal tract involvement and a rectal temperature of $89^{\circ} \mathrm{F}$.

A temperature of $100^{\circ} \mathrm{F}$ or more was found in four suicidal patients $(5.0 \%)$ and two accidental $(3.4 \%)$. The highest recorded temperature of $105^{\circ} \mathrm{F}$ accompanied the delayed development of severe, persisting parkinsonism in a 27 -year-old man.

Gastro-intestinal. Nausea or vomiting occurred in ten suicidal patients $(12.6 \%)$ and eleven accidental $(18.9 \%)$. The exposure had usually been mild.

Cardiovascular. Sixteen suicidal patients $(20.0 \%)$ had pulse rates in excess of $100 / \mathrm{min}$, one patient showing multiple extrasystoles. Three patients $(3.8 \%)$ were in shock. Deep vein thrombosis occurred in two patients $(2.5 \%)$ within $48 \mathrm{hr}$ of admission and one patient died from subsequent pulmonary infarction.

Of the 'accidental' group, five $(8.6 \%)$ had a tachycardia, one $(1.7 \%)$ was in shock, and one patient presented with congestive cardiac failure.

Respiratory. Acute respiratory congestion was found in eight suicidal patients $(10.0 \%)$ and two accidental $(3 \cdot 4 \%)$.

Neurological. (a) Coma. In the majority of patients exposure to carbon monoxide produced impairment of consciousness. At the time of admission nineteen suicidal $(23.8 \%)$ and eleven accidental patients $(18.9 \%)$ were considered to be either semi-comatose or comatose.

(b) Pyramidal signs. Signs of pyramidal tract involvement were uncommon. Bilateral involvement was found in two suicidal $(2.5 \%)$ and four accidental patients $(6.9 \%)$, whereas unilateral involvement was indicated in four suicidal patients $(5.0 \%)$ and three accidental $(5 \cdot 2 \%)$.

Severe hemiplegia developed in four patients. Two of these were thought to have suffered cerebrovascular accidents whilst lighting gas fires, though the possibility that the hemiplegia was the result rather than the cause of exposure to carbon monoxide could not be refuted. The other two cases are worthy of further mention here.

\section{Case 1}

A 65-year-old woman took an overdose of barbiturates and chlorpromazine in addition to gassing herself. On admission she was deeply comatose and shocked, had absent deep reflexes and bilateral extensor plantar responses. Her pupils were constricted and showed no reaction to light. Laboratory tests revealed a carboxy-haemoglobin level of $10 \%$, serum barbiturate equivalent to $5 \cdot 8$ $\mathrm{mg} / 100 \mathrm{ml}$ amylobarbitone (Amytal) and blood glucose of $348 \mathrm{mg} / 100 \mathrm{ml}$. There was no history of diabetes. Two days after admission a massive right 
cerebral haemorrhage resulted in a left hemiplegia. The following day she died.

\section{Case 2}

A 27-year-old man regained consciousness quickly after his suicidal exposure but remained delirious for 13 days before relapsing into an akinetic mute state. Two days later the development of a left hemiplegia and an enlarged right pupil suggested tentorial herniation. By the 18th day, however, the neurological state returned to normal and his level of consciousness increased to reveal a persistent dementing process. From the eighth to the eighteenth day the presence of tremor of the hands and $\operatorname{cog}$ wheel rigidity of the limbs indicated extrapyramidal involvement.

(c) Extrapyramidal signs. Two patients developed extrapyramidal signs. In one case (Case 2) these were transient. The following case demonstrates the development of persistent parkinsonism.

\section{Case 3}

A 27-year-old man had deliberately exposed himself to the exhaust fumes of his car. On admission his initial coma rapidly gave way to a persisting delirium. Eighteen days after exposure he relapsed with the development of symmetrically increased reflexes of both arms, absent reflexes in the lower limbs, a right extensor plantar response, and an intention tremor and a resting tremor of all limbs.

Over the next 4 days he had a pyrexia of 103$105^{\circ} \mathrm{F}$, his pyramidal signs abated and a full parkinsonism picture developed with gross tremor and $\operatorname{cog}$ wheel rigidity.

By the 4th week his pyrexia and delirium cleared leaving a severe dementia and persistent parkinsonism.

(d) Other neurological abnormalities. Pupillary abnormalities-usually constricted pupils with sluggish or absent reaction to light-occurred in $10.0 \%$ of suicidal and $10.3 \%$ of accidental patients. Transient deafness was observed in one patient and incontinence was a feature in six patients, two having combined urinary and faecal incontinence.

(e) Mental state. When the patient regained consciousness, disturbances in the mental state were noted. With suicidal patients psychiatric opinion was always sought.

Table 5 lists the major abnormal findings. As one would expect, such abnormalities were more common in the suicidal population, yet one third of the suicidal patients were considered to be free of organic or affective disturbance at the time of interview; these included a number of people with previously stable personalities who, on severe provocation, had impulsively attempted suicide and a further group comprising 'character disorders'
TABLE 5. Mental state examination

\begin{tabular}{|c|c|c|c|}
\hline & Suicidal & Accidental & Total \\
\hline \multirow{6}{*}{$\begin{array}{l}\text { Irritability/restlessness* } \\
\text { Depression } \\
\text { Anxiety } \\
\text { Prolonged delirium } \\
\text { Total showing } \\
\text { abnormal mental } \\
\text { state }\end{array}$} & $23(28.8 \%)$ & $6(10 \cdot 3 \%)$ & $29(21.0 \%)$ \\
\hline & $25(31 \cdot 3 \%)$ & $1(1.7 \%)$ & $26(18 \cdot 8 \%)$ \\
\hline & $6(7 \cdot 5 \%)$ & & $6(4 \cdot 3 \%)$ \\
\hline & $17(21.3 \%)$ & $11(18.9 \%)$ & $28(20 \cdot 3 \%)$ \\
\hline & & & \\
\hline & $54(67 \cdot 5 \%)$ & $16(27 \cdot 6 \%)$ & $70(50 \cdot 7 \%)$ \\
\hline
\end{tabular}

*These categories are not mutually exclusive, e.g. a patient may be described as both depressed and delirious.

who, often under the influence of alcohol, made an impulsive attempt.

An important finding was the high incidence of persisting delirium in both suicidal and accidental patients. In $21.3 \%$ of suicidal patients and $18.9 \%$ of accidental patients this delirium was prolonged for periods ranging from many hours to 4 weeks, indicating continuing interference with cerebral function.

These patients were characteristically disorientated for time and place, with poor attention and concentration, impaired grasp and disordered thinking. Visual hallucinations occurred in one patient. Two of these patients had never been comatose.

Prolonged delirium was reported in $22.9 \%$ of males and $16.4 \%$ of females. It was significantly more common in the older age groups and those with previous neurological disease.

The affective accompaniment to the delirium is shown in Table 6. The patients were commonly described as irritable and restless and often became

TABLE 6. Affective accompaniment to delirium

\begin{tabular}{llll}
\hline & Suicidal & Accidental & \multicolumn{1}{c}{ Total } \\
\hline Irritable/restless & $7(41.2 \%)$ & $2(18 \cdot 2 \%)$ & $9(32 \cdot 1 \%)$ \\
Depression & $2(11.8 \%)$ & 0 & $2(7 \cdot 1 \%)$ \\
Anxiety & $1(5.9 \%)$ & 0 & $1(3.6 \%)$ \\
\hline
\end{tabular}

violent. A number of patients on regaining consciousness displayed irritable, aggressive and uncooperative behaviour and discharged themselves from hospital before a full psychiatric examination could be carried out. Possibly some of these were delirious.

\section{Outcome}

Of the 138 patients, three died in hospital. All three were women over 65 ; one died from a massive cerebral haemorrhage, one from bronchopneumonia and the third from a pulmonary embolus secondary to a femoral vein thrombosis.

Permanent defects were observed in five patients. Three men developed dementia, one with parkinsonism. Spastic hemiplegia occurred in a 70-yearold male and an 85-year-old female although the 
possibility remains that the hemiplegia may have immediately preceded exposure.

\section{Management}

Following treatment in the Casualty Department $76.2 \%$ of the suicidal group, but only $27.6 \%$ of the accidental group, were admitted to other medical or psychiatric wards. Admission appeared to be determined more by psychiatric than by medical considerations. Carboxyhaemoglobin levels were estimated in only $32.5 \%$ of suicidal and $24.1 \%$ of accidental patients, and oxygen was received by no more than $43.8 \%$ of suicidal and $34.5 \%$ of accidental patients. In some cases oxygen therapy was abandoned because the patient was irritable and resisted treatment. Therapy was withheld for this reason in Case 2 despite a carboxyhaemoglobin $(\mathrm{COHb})$ level on admission of $42 \%$. In others both $\mathrm{COHb}$ estimation and oxygen therapy were considered unnecessary because the patient was conscious on admission.

Out-patient follow-up was received by $73.8 \%$ of suicidal patients and appeared to be dictated principally by their psychiatric state. In the accidental group only $8.6 \%$ were subsequently seen.

\section{Discussion}

Bour et al. (1966) in a study of 290 cases of severe carbon monoxide poisoning reported that the earliest and commonest neurological accompaniment to the comatose state was a tonic and particularly hypertonic disorder, decerebrate rigidity being not uncommon. This alteration of tone was generally accompanied by increased tendon reflexes and extensor plantar responses, and less frequently by extrapyramidal signs. A state resembling akinetic mutism was reported in nine patients on emergence from coma, all with fatal outcome.

In the present series which included patients of all degrees of severity, tonic and reflex changes were uncommon and decerebrate rigidity did not occur. Extrapyramidal signs occurred transiently in Case 2 and persisted in Case 3. Akinetic mutism occurred in one patient (Case 2) following a 13-day period of delirium.

Twenty per cent of the survivors $(13.6 \%$ of the total cohort) in this study suffered a prolonged delirium, an incidence considerably higher than that given by Shillito et al. (1936) for the equivalent 'confusional psychosis'. A relapsing course occurred in two patients (Cases 2 and 3) though they were observed to be delirious throughout the interval between exposure and the development of further neurological abnormality.

Cortical damage, in the form of dyspraxia and dysphasia accompanying a dementing process, was evident in three patients on regaining consciousness.
The nature of the transient deafness observed in one case could not be established in retrospect.

The hyperglycaemia which developed in one woman who was not a known diabetic (Case 1, may have been unrelated to the carbon monoxide exposure, though Bour et al. (1966) regard hyperglycaemia as a not uncommon occurrence in the acute phase of carbon monoxide poisoning. Gaultier et al. (1964) described a case of acute pancreatitis with hyperglycaemia following acute poisoning and suggested that carbon monoxide may have a direct toxic effect on the pancreas; however, the occurrence of hyperglycaemia with other forms of acute cerebral insult-e.g. subarachnoid haemorrhage (Walton, 1956), suggests that cerebral and particularly hypothalamic damage is involved.

Excluding the two cases of hemiplegia whose aetiology remain in doubt, three patients $(1.5 \%$ of the total cohort) suffered permanent neuropsychiatric damage, an incidence far in excess of previous reports. The follow-up of this population now in progress may well reveal further cases initially undetected or developing late sequelae.

The clinical severity and mortality were similar in both the accidental and suicidal groups. Among patients presenting for treatment death was uncommon but the frequent occurrence of prolonged delirium suggests that all degrees of functional and structural damage may have occurred and that all cases deserve active treatment in the hope that the risk of sequelae may be reduced.

Oxygen therapy, however, was administered to only $43.8 \%$ of the suicidal patients and to $34.5 \%$ of the accidental cases and in no case was an intravenous hypertonic solution used to reduce cerebral oedema. There was often a failure to appreciate the gravity of carbon monoxide poisoning, partly based on the questionable belief that, if the patient survives, his recovery is complete, and in part on the failure to appreciate that the complex formed by carbon monoxide and haemoglobin molecules can be efficiently dissociated by oxygen therapy.

A reduction in the carbon monoxide content of domestic gas offers the best prospect of reducing the morbidity associated with this type of poisoning. However, incomplete combustion of any domestic fuel may produce lethal quantities of carbon monoxide, and industrial accidents will continue to occur. It is, therefore, imperative that carbon monoxide poisoning should always be regarded as a medical emergency calling for prompt and effective treatment.

Treatment should commence as soon as possible after removal from the source of the gas and ambulances should be equipped to administer oxygen whilst in transit to hospital or a designated poisoning treatment centre (Ministry of Health Report on 
Hospital Treatment of Acute Poisoning, 1968). In the absence of hyperbaric facilities the most efficient form of oxygenation appears to be a mixture of $95 \%$ oxygen and $5 \%$ carbon dioxide administered through an apparatus which prevents rebreathing of carbon monoxide (Douglas et al., 1962). On arrival at hospital the level of carboxyhaemoglobin should be estimated. In view of the fact that up to $20 \%$ of suicidal patients may also have taken a drug overdose, barbiturate and salicylate estimations may be advisable as a routine procedure. Oxygenation should certainly continue until the carboxyhaemoglobin level has fallen to zero and may be beneficial beyond this point in patients with evident cerebral dysfunction. Intravenous hypertonic solutions or dexamethasone are indicated wherever there is any suspicion of cerebral oedema. Careful assessment of the mental state of patients showing irritable, restless or aggressive behaviour may reveal evidence of delirium which calls for compulsory detention under Section 30 of the Mental Health Act, 1959, if the patient is intent upon leaving the hospital. Follow-up facilitics should be provided by the hospital staff or general practitioner in the anticipation of a relapsing course or the development of late neuropsychiatric sequelae.

\section{Acknowledgments}

We are grateful to all of our colleagues in the region who have given us free access to clinical records and have willingly shared their experiences with us. One of us (J.S.S.) is sup- ported by a grant from the Scientific and Research Committee of the Royal Victoria Infirmary and the other (S.B.) formerly the Nuffield Foundation Fellow in Psychiatry in the University of Newcastle is currently Reader in Psychiatry at the University of Manchester.

\section{References}

Bour, H., Pasquier, P. \& Bertrand-Hardy, J.M. (1966) Le coma oxycarboné. Etude générale, clinique, biologique et thérapeutique de 290 cas. Semaine des Hôpitaux de Paris, 42, 1839.

Douglas, T.A., Lawson, D.D., Ledingham, I.McA., Norman, J.N., Sharp, G.R. \& Smith, G. (1962) Carbon monoxide poisoning. A comparison between the efficiencies of oxygen at one atmosphere pressure, of oxygen at two atmospheres pressure and of $5 \%$ and $7 \%$ carbon dioxide in oxygen. Lancet, i, 68 .

Garland, H. \& Pearce, J.M.S. (1967) Neurological complications of carbon monoxide poisoning. Quarterly Journal of Medicine, 36, 445.

Gaultier, M., Fournier, Et., Gervais, P. \& Bcdin, F. (1964) Encéphalopathie pancréatique survenue au décours d'une intoxication oxycarbonéz. Comparaison avec l'encéphalopathie post-intervallaire de l'intoxication oxycarbonée. Presse Médicale, 72, 3263.

Hospital Treatment of Acute Poisoring (1968) Report of the Joint Sub-Committees of the Central Health Services Council and Scottish Health Services Council. Her Majesty's Stationery Office, London.

Meigs, J.W. \& Hughes, J.P.W. (1952) Acute carton monoxide poisoning. An analysis of one hundred and five cases. Archives of Industrial Hygiene and Occupational Medicine, 6, 344.

Shillito, F.H., Drinker, C.K. \& Shaughnessy, T.J. (1936) The problem of nervous and mental sequelae in carbon monoxide poisoning. Journal of the American Medical Association, 106, 669.

Walton, J.N. (1956) Subarachnoid Haemorrhage, p. 86 Livingstone, Edinburgh and London. 